\title{
The Accuracy and Precision of an Open-Circuit System To Measure Oxygen Consumption and Carbon Dioxide Production in Neonates
}

\author{
KEITH H. MARKS, PATRICIA COEN, JAMES R. KERRIGAN, NICK A. FRANCALANCIA, \\ ELIZABETH E. NARDIS, AND MICHAEL T. SNIDER \\ Department of Pediatrics and Anesthesia, The Milton S. Hershey Medical Center, The Pennsylvania State \\ University College of Medicine, Hershey, Pennsylvania 17033
}

\begin{abstract}
We measured the oxygen consumption, carbon dioxide production, and respiratory quotient during the combustion of a known mass of anhydrous ethanol and methanol to assess the accuracy of an open-circuit flowthrough system. Continuous measurements were made of the mass of alcohol burned, the velocity of gas flow through the apparatus, and simultaneous measurements of the fractional concentration of oxygen, carbon dioxide and nitrogen of the inlet and outlet gas using paramagnetic oxygen analyzer, infrared carbon dioxide meter, and mass spectrometer. Standard respiratory and stoichiometric equations were used to calculate the oxygen consumption, carbon dioxide production and $R Q$ for the mass of absolute alcohol combustion per unit time. In a series of 12 consecutive laboratory experiments (on 7 days), the measured values of gas exchange (similar to the rate of respiratory gas exchange by an infant of 1-4 kg) were in agreement within $5 \%$ of the true values for ethanol and methanol combustion, confirming the validity of the open-circuit method. The paramagnetic oxygen analyzer and the mass spectrometer gave similar oxygen consumption results and differed very little when the rate of absolute alcohol combustion was used to quantify the accuracy of the complete measurement system. A positive measurement error was observed for the carbon dioxide production results from both the IR meter and mass spectrometer, with the result that the respiratory quotient measurements were $3.4-4.7 \%$ higher than the true value. The mass spectrometer gave more precise oxygen consumption results, whereas smaller variance of carbon dioxide production measurements was observed using the infrared $\mathrm{CO}_{2}$ meter. The sources of error and methods to reduce the overall system error were considered. By using a rigorous set of calculations we showed that the rate of combustion of a known mass of absolute alcohol was a suitable laboratory method for validation of respiratory gas exchange measurements made in the neonate. (Pediatr Res 21: 58-65, 1987)
\end{abstract}

\section{Abbreviations}

VัO $\mathrm{O}_{2}$, oxygen consumption

$\dot{\mathrm{V}} \mathrm{CO}_{2}$, carbon dioxide production

RQ, respiratory quotient

$\dot{V}$, volumetric flow rate

Received December 5, 1984; accepted August 25, 1986

Address correspondence and reprint requests to Keith H. Marks, Department of Pediatrics. The Milton S. Hershey Medical Center. Hershey, PA 17033.

Supported by a grant from the Whitaker Foundation and from the National Institute of Child Health and Human Development (HD-16399). J. R. K. was aided by the Summer Science Research Program for Medical Students Grant 8-8188 from March of Dimes Birth Defects Foundation.
STPD, standard temperature, standard pressure, dry IR, infrared

The requirements for the accurate determination, and the sources of error in clinical studies of metabolic rate in man were laid down in detail over 75 yr ago by Atwater and Benedict, and in infants by Levine, Gordon, Karlberg, and Brück (1-6). The extraordinarily complex calibration equipment and the detailed calibration results these authors published have rarely been quoted in contemporary neonatology literature (7). Moreover, the open-circuit systems currently used to measure metabolic rate of the newborn when only the head or face of the baby was enclosed in a chamber or mask have yet to be routinely calibrated in a standard manner.

In our study, we describe a method to measure $\dot{\mathrm{VO}}_{2}, \dot{\mathrm{V}} \mathrm{CO}_{2}$, and $R Q$ with the flow-through system in a controlled laboratory environment when the rate of absolute alcohol combustion was used to quantify the accuracy of the complete measurement system. In addition to our major objective of evaluating the whole open-circuit system, we also partitioned the accuracy and precision of the gas measurements among the individual constituent components of the system, i.e. paramagnetic oxygen analyzer, $\mathrm{CO}_{2}$ infrared absorption analyzer, gas chromatograph, and mass spectrometer after each instrument had been calibrated against gases of known composition. The dynamic responsiveness of the whole system was also determined. The data from our testing procedures were relatively easy to obtain, and with appropriate care, ethanol and methanol combustion can be used regularly to validate the overall function and accuracy of the open-circuit system.

\section{MATERIALS AND METHODS}

The open-circuit system we used was developed from those previously described. In principle, it consists of drawing room air through a hood or mask placed over a baby's head or face at a constant rate (8-10). The output stream of expired gas mixed with air was collected and passed through a drying chamber before analysis of $\mathrm{O}_{2}, \mathrm{CO}_{2}$, and $\mathrm{N}_{2}$ concentration. The values for $\dot{\mathrm{VO}}_{2}$ and $\mathrm{VCO}_{2}$ were calculated from measurements of the amount and composition of the inspired and expired gas stream using respiratory gas equations for the open-circuit method at STPD conditions (11). In the combustion experiments, a flame and chimney were substituted for the infant-hood or mask setup. During the alcohol burn, oxygen, carbon dioxide, and nitrogen concentrations of the input and output gas stream were measured for about $90 \mathrm{~min}$ at a time when all recordings of flow rate, $\mathrm{O}_{2}$, 
$\mathrm{CO}_{2}$, and nitrogen concentrations, temperature, and pressure were completely stable. The mass of absolute alcohol combustion per unit time was the laboratory standard used to test the accuracy and precision of the measured $\dot{\mathrm{VO}}_{2}, \dot{\mathrm{V}} \mathrm{CO}_{2}$, and $\mathrm{RQ}$ by the Student's $t$ test, regression, and correlation analysis (12).

Basic to our protocol was the maintenance of a steady flow of air into, through, and out of the combustion chamber while continuously monitoring the mass of materials taking part in the combustion reaction. Based on the law that energy was conserved, we predicted that there would be no accumulation or depletion of either mass or energy within the apparatus, and that all material and energy balances would be of the simple type: [rate of species out] - [rate of species in] = [rate of internal production]. Using the following series of steps, each factor in the combustion equation was reduced to a function of the base units of mass, time, temperature, or mole quantity for all the materials taking part in the steady flow process. The complete open-circuit system including test equipment is shown diagramatically in Figure 1. A representative recording strip during an alcohol burn is shown in Figure 2.

Calibration of Component Parts. $\dot{V}$. The velocity of air flowing through the system was determined using the rate of evacuation of a calibrated precision volume spirometer as the primary standard. A flow rate of 2-5 liter $\mathrm{min}^{-1}$ was chosen because it was approximately 10-20 times the minute volume of the infants used in clinical studies, enough to prevent hyperventilation due to the rebreathing of accumulated $\mathrm{CO}_{2}$.

The inlet of the fixed orifice flowmeter F (Fisher and Porter, Warminster, PA, no. 10A9010) was connected to the outlet of a 7 liter Tissot spirometer by wide bore $(30 \mathrm{~mm})$ respiratory tubing and a T-shaped stopcock (Warren E. Collins, Inc., Braintree, MA, nos. 73213 and 21043). Fine-adjustment needle valves $Z_{1}$ and $\mathrm{Z}_{2}$ (Allentown Valve Co., Emmaus, PA, Nupro type B-4L2) placed on the outlet side of the flowmeter $F$ were used to regulate airflow generated by the blower b1 (Rotron Inc., Woodstock NY, series 329AS) through the system so that the equator of the stainless steel spherical float remained constant on the fixed scale of the flowmeter F. Room air was allowed to reach a steady flow through the system for at least $60 \mathrm{~min}$. Repeated volume collections were made from the spirometer with the aid of a stopwatch. The accuracy of the flow meter was determined by repeated measurements of the rate of evacuation of the spirometer, and the stability of the air flow generated by the blowers through the system was assessed by noting that the line inscribed by the pen attached to the spirometer was straight over the entire evacuation period.

The spirometer gas volume was reduced to STPD by the formula:

$$
\frac{\mathrm{p}_{1} \mathrm{v}_{1}}{\mathrm{~T}_{1}}=\frac{\mathrm{p}_{2} \mathrm{v}_{2}}{\mathrm{~T}_{2}}
$$

Where $\mathrm{p}_{\mathrm{I}}=760(\mathrm{~mm} \mathrm{Hg})$

$\mathrm{v}_{1}=$ gas volume STPD (liters)

$\mathrm{T}_{1}=273.15\left({ }^{\circ} \mathrm{K}\right)$

$\mathrm{p}_{2}=$ ambient barometric pressure $(\mathrm{mm} \mathrm{Hg})-\mathrm{pH}_{2} \mathrm{O}$ $(\mathrm{mm} \mathrm{Hg})$

$\mathrm{v}_{2}=$ spirometer volume (liter)

$\mathrm{T}_{2}=$ temperature of mixing chamber $\left({ }^{\circ} \mathrm{C}\right)+273.15$

$\mathrm{pH}_{2} \mathrm{O}=$ vapor pressure of water $(\mathrm{mm} \mathrm{Hg})$ at temperature of mixing chamber $\left({ }^{\circ} \mathrm{C}\right)$,

or $v_{1}=$ gas volume STPD (liter) $=\frac{v_{2} \times p_{2}}{T_{2}} \times \frac{T_{1}}{p_{1}}$

The calculation to convert volumes to STPD conditions defines the equation of state of the air in the outlet stream of the flowthrough system.

Gas standards. Known gas mixtures similar in composition to the actual gases collected during the combustion experiment were used to calibrate the gas analyzers. A careful gas calibration was performed immediately prior to the experimental session and was checked immediately after the experiment (Fig. 2). The purity and $\mathrm{CO}_{2}$ content of all calibration gases were ascertained by gas-solid chromatography.

A gas chromatograph with a $1.92 \mathrm{~m}$ long, $0.63 \mathrm{~cm}$ outer diameter column of polymer (Porapak Q) packing was calibrated using $100 \% \mathrm{CO}_{2}$. Peak areas and heights were measured with a Spectra-Physica 4100 automated integrator. The trace amount of oxygen and argon in the standard $\mathrm{CO}_{2}$ tank was less than $0.015 \%$ and the trace nitrogen was less than $0.015 \%$. For calculations, concentration of this tank was therefore taken to be $99.97 \%$ carbon dioxide. Analysis was performed with a carrier gas of helium with a flow greater than $100 \mathrm{ml} \mathrm{min}^{-1}$ and a pressure of $1.76 \mathrm{~kg} \mathrm{~cm}^{-2}$ in a room temperature water bath to control for fluctuations in ambient temperature. Representative retention time for $\mathrm{CO}_{2}$ was $1.5 \mathrm{~min}$ under these conditions. Minimal detectable level for $\mathrm{CO}_{2}$ was $0.004 \%$. The $\mathrm{CO}_{2}$ standard tank used to calibrate the infrared $\mathrm{CO}_{2}$ analyzer and mass spectrometer was assayed using this technique a total of thirteen times against $100 \% \mathrm{CO}_{2}$. It was found to have a mean $\mathrm{CO}_{2}$ concentration of $1.041 \%$ with a SD of $0.18 \%$. Gas chromatography was also used to assay the purity of oxygen and nitrogen used for calibration of the mass spectrometer. High purity oxygen (Liquid Carbonics Corporation, Collingswood, $\mathrm{NJ}$ ) was found to have trace levels of argon of $0.13 \%$. This assay was accomplished with a $91.4 \mathrm{~cm}$ long, $0.63 \mathrm{~cm}$ outer diameter column of Molecular Sieve $5 \mathrm{~A}$ packing at a temperature of $-70^{\circ} \mathrm{C}$. High purity nitrogen also from Liquid Carbonics was assayed with a $91.4 \mathrm{~cm}$ long, $0.63 \mathrm{~cm}$ outer diameter column of Molecular Sieve $5 \mathrm{~A}$ at $0^{\circ} \mathrm{C}$, and found to have less than $0.015 \%$ oxygen and argon.

Paramagnetic oxygen analyzer. Linearity of the Servomex oxygen analyzer was established with nitrogen $(99.985 \%$ pure) and room air $(20.93 \% \pm 0.02 \%)$ as the calibrating gases. A difference representing a $1 \%$ deflection on the Servomex could be read as a $100 \%$ deflection on the recorder. A high grade gravimetric mixture of oxygen and nitrogen and analyzed to be free of contaminants, was used as a third standard (see Fig. 2). The composition of the certified (gravimetric method) $\mathrm{O}_{2} / \mathrm{N}_{2}$ gas mixture used to calibrate the $\mathrm{O}_{2}$ analyzer was $20.28 \pm 0.02 \%$ $\mathrm{O}_{2}$ /balance $\mathrm{N}_{2}$ when calibrated against the nitrogen tank $(99.985 \%)$ and room air $(20.93 \pm 0.02 \%)$. The same $\mathrm{O}_{2} / \mathrm{N}_{2}$ gas mixture was used in all of the experiments. We found that the Servomex gas analyzer was subject to zero drift and variations in sensitivity. For this reason an "electrical calibration" with a known input signal was performed frequently (q $15 \mathrm{~min}$ ) to ensure that the baseline value had not drifted below the minimal level on the meter (see Fig. 2).

$\mathrm{CO}_{2}$ analyzer. We established the linearity of the $\mathrm{CO}_{2}$ infrared absorption analyzer between $0 \% \mathrm{CO}_{2}$ and $1.041 \% \mathrm{CO}_{2}$ using a hypersonic blender (ADC gas diluter Model GD 600, PK Morgan Instruments, $\mathrm{N}$. Andover, MA). The correlation of diluted versus measured $\mathrm{CO}_{2}$ was 0.99 . The $\mathrm{CO}_{2}$ meter was calibrated in each experiment against $99.985 \%$ nitrogen and $1.041 \% \mathrm{CO}_{2}$ concentration gas. By changing position of the stopcock S (see Fig. 1) deflections could be measured between the mixed output stream gas and room air, room air and room air drawn through sodalime, and for the $\mathrm{CO}_{2}$ and $\mathrm{N}_{2}$ calibrating gas (see Fig. 2).

Mass spectrometer. The mass spectrometer was calibrated prior to each trial with mixtures of $99.87 \% \mathrm{O}_{2}$ or $99.985 \% \mathrm{~N}_{2}$. By averaging the digitized signals the oxygen and nitrogen concentration were estimated within $0.02 \%$ of the $20.28 \%$ gravimetric standard tank. Measurements of room air made within the laboratory indicated oxygen concentrations of $20.93 \pm$ $0.02 \%$.

Validation Experiments. Herein we obtained data about the overall performance characteristics of the open-circuit system over a range of $\dot{\mathrm{VO}}_{2}$ and $\dot{\mathrm{V}} \mathrm{CO}_{2}$ values that closely mimic those found in the neonate. The measurement error of the complete system was calculated by the difference between the measurement and the true value (Table 1). The true value refers to the 


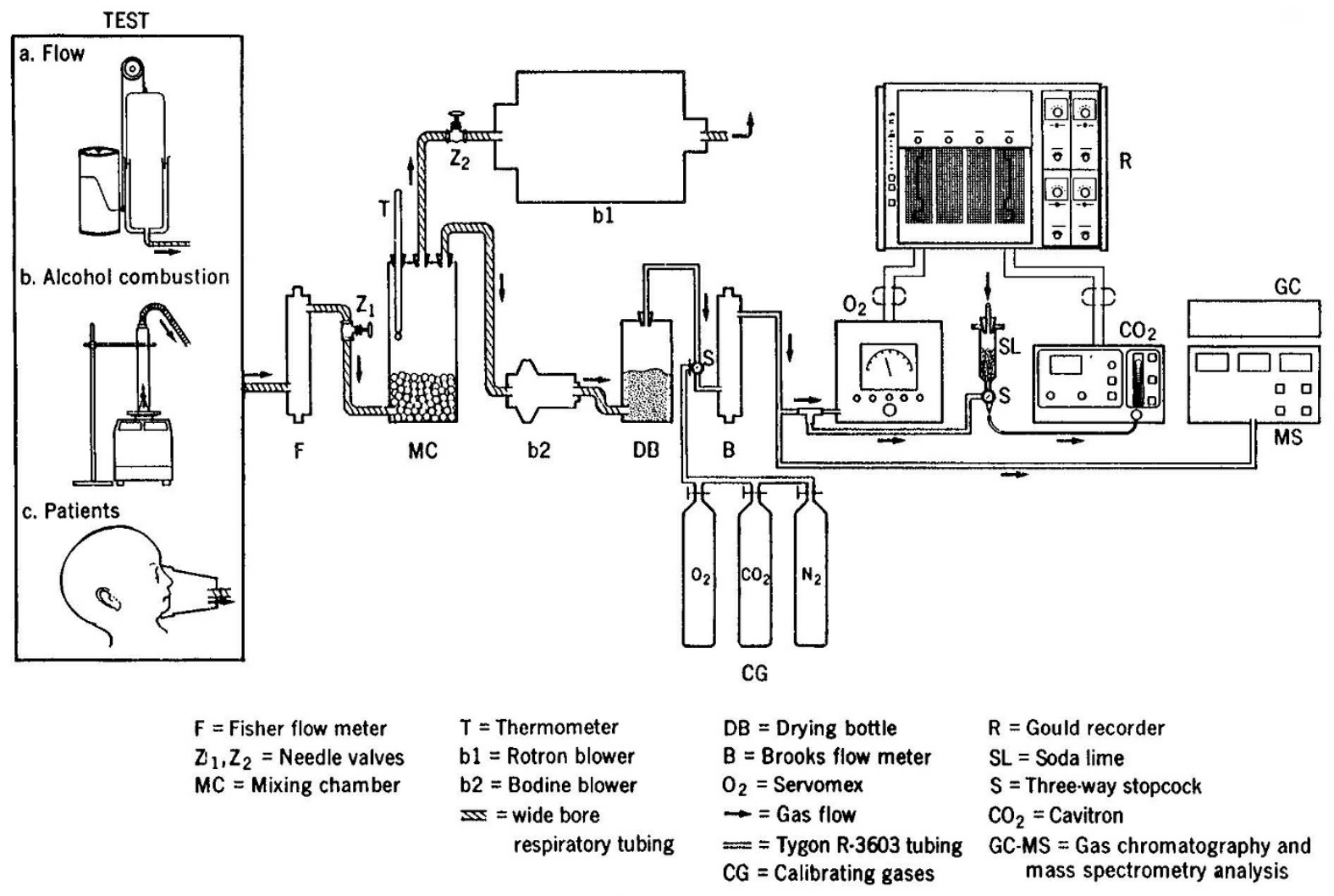

Fig. 1. $\dot{\mathrm{VO}}_{2}$ and $\dot{\mathrm{VCO}}_{2}$ open-circuit system.

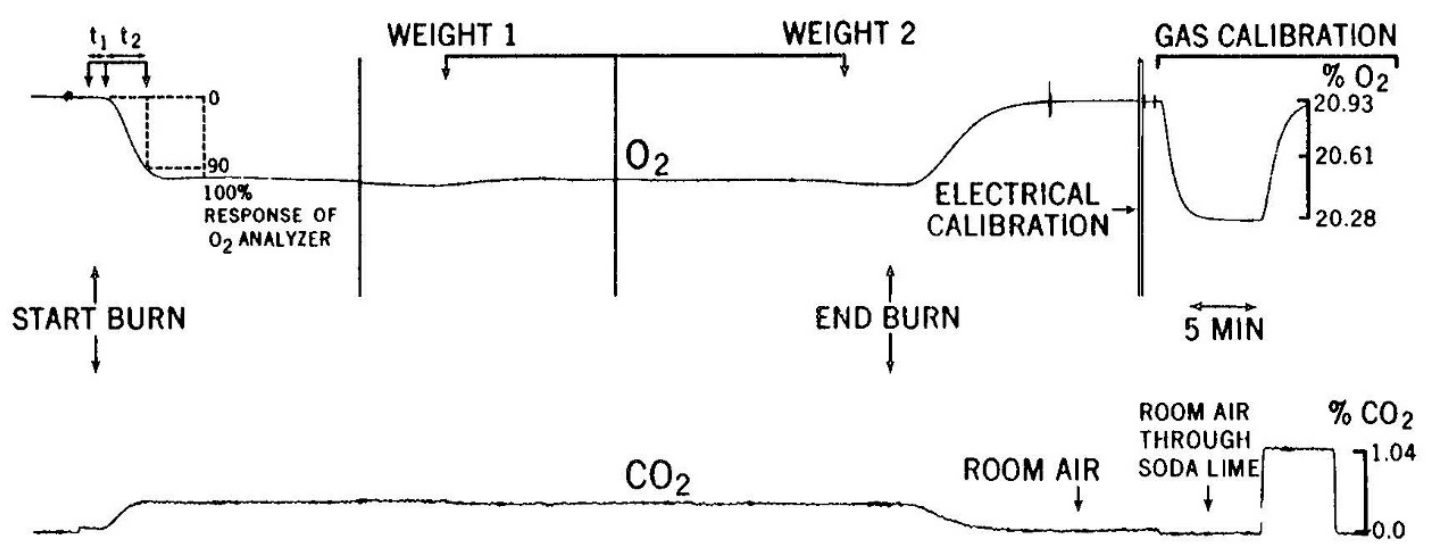

Fig. 2. Typical $\mathrm{O}_{2}(t o p)$ and $\mathrm{CO}_{2}$ output traces during an alcohol burn. Deflections were determined as the vertical distance between the baseline (drawn through the points before and after the deflection readings) and the deflection line parallel to it. The percentage of oxygen and carbon dioxide per $\mathrm{mm}$ deflection on the chart recorder was calculated from the number of mm deflection of the known percentage of oxygen and carbon dioxide in the calibration gases. During an experiment, oxygen and carbon dioxide composition was determined for exactly 30 min after ignition (weight 1 ) and before extinction of the flame (weight 2 ). $t_{1}, t_{2}=$ delay time, \% step response time, respectively. The electrical calibration represents a known input signal to prevent zero drift of the highly sensitive paramagnetic $\mathrm{O}_{2}$ analyzer.

$\dot{\mathrm{V}} \mathrm{O}_{2}$ and $\dot{\mathrm{V}} \mathrm{CO}_{2}$ values that were obtained from an exemplar method, i.e., the rate of absolute alcohol combustion agreed on by investigators as being sufficiently accurate to quantify the overall measurement error of a multiple component system as precisely as possible $(1-6,8,13-16,18,19,22,23)$.

Alcohol. Only ethanol showing no benzene contamination as determined by scanning spectrophotometer $(230-270 \mathrm{~nm})(17)$ or high-pressure liquid chromatography grade methanol (mole purity not less than $99.9 \%$ ) were used. Care in handling the ethanol $\left(\mathrm{CH}_{3} \mathrm{CH}_{2} \mathrm{OH}\right)$ and methanol $\left(\mathrm{CH}_{3} \mathrm{OH}\right)$ was essential since the alcohol was hygroscopic; once a bottle was opened and the alcohol exposed to air, its water content increased. The relative density of the alcohol was therefore determined in each experiment by pycnometry (18) so that the anhydrous mass of alcohol consumed during the burn was used in the calculations (19).

A density bottle (8350-B10 Pycnometer, Arthur H. Thomas Company, Philadelphia, PA), carefully dried, was weighed empty; then the flask was filled with alcohol (Publicker Chemical Corp., Greenwich, CT; Fisher Scientific Company, Pittsburgh, PA) and the stopper was replaced observing that the alcohol was forced up the capillary so that the bottle then contained a fixed volume of the alcohol. The outside of the bottle was wiped dry and its mass determined again. The difference between the mass of the flask when full and when empty gave the mass of alcohol. The density bottle was then emptied, rinsed and filled with distilled water. The mass of water filling the bottle may thus be found. 
The internal volume of the density bottle

$$
\text { (v) = mass of water at } \mathrm{T} \times \frac{1}{\text { density of water at } \mathrm{T}(20)},
$$

where $\mathrm{T}$ is the $\mathrm{C}$ temperature.

Let: $\mathrm{m}_{\mathrm{a}}=$ mass of alcohol; $\mathrm{m}_{\mathrm{w}}=$ mass of water; $\mathrm{v}=$ internal volume of the bottle; $\rho=$ relative density of alcohol.

Then

$$
\begin{gathered}
\rho=\frac{\text { density of alcohol at } \mathrm{T}}{\text { density of water at } \mathrm{T}} \\
\rho=\mathrm{m}_{\mathrm{a}} / \mathrm{v} / \mathrm{m}_{\mathrm{w}} / \mathrm{v} .
\end{gathered}
$$

The density measurements will change with temperature because the volume changes with temperature. The coefficient of volume expansion for alcohol is approximately four times as great as for water corresponding to a change of about 0.0008 unit in density per ${ }^{\circ} \mathrm{C}$. We corrected the result for temperature by adding 0.0008 to the observed value of the relative density of the alcohol per ${ }^{\circ} \mathrm{C}$ above the standard $\left(20^{\circ} \mathrm{C}\right)(18)$. The anhydrous concentration of the alcohol solution ( $\mathrm{g}$ alcohol/100 $\mathrm{g}$ solution) was determined from tables of standard values for the relative density of alcohol (21).

The mass of alcohol burned during the experiment was multiplied by the anhydrous alcohol concentration (\%) to yield the mass of absolute alcohol burned/unit time for each experiment (19).

Alcohol lamp. A 10-ml Pyrex Erlenmeyer flask was filled partially with alcohol to cover the end of a glass capillary tube containing a fine glass wick. The $5-\mathrm{cm}$ long capillary tube (cut from a $50 \lambda$ micro pipette) with its glass wick acted as the burner and was held firmly in place by a rubber stopper. A 22-gauge hypodermic steel needle (not shown in Figure 1) was used as an air inlet to keep the flame constant. The combustion chamber consisted of a Pyrex glass tube $(35 \mathrm{~cm}$ long, $5 \mathrm{~cm}$ diameter) mounted vertically over the alcohol lamp using a support stand and pinch clamp. After lighting the flame, the chimney was lowered to within about $5 \mathrm{~mm}$ of the load plate of the "threeplace electronic balance" (Sartorius 11371332 Balance 1205MPBCD, VWR Scientific, Bridgport, NJ) and must not touch either the lamp or the load plate of the balance during the entire experiment. With this balance, the mass of alcohol combusted of about $0.4 \mathrm{~g} / 30$ min was measured with an accuracy of better than $0.1 \%$. The top end of the combustion chamber was connected to the open-circuit system using wide bore respiratory tubing and an air tight seal as shown in Figure 1. Complete combustion of the alcohol was assumed when a completely blue and even flame was observed (22).

The weight of the alcohol lamp was determined after ignition (weight 1) and before extinction of the flame (weight 2). The exact timing of these events were recorded on the chart paper (see Fig. 2).

Gas sampling and analysis. Before each combustion experiment the open-circuit system was kept running overnight at a constant air temperature, and air flow was maintained through the analyzers at a constant rate to insure adequate warm up time and a steady baseline output on the recording system.

The 5-liter plexiglas mixing cylinder (filled with glass marbles) specially constructed for this open-circuit system was used to integrate the variations in the expired gas fraction before reaching the gas analyzers. The mixing cylinder was at a pressure slightly below barometric (U-tube manometer reading $=-3 \mathrm{~cm} \mathrm{H} \mathrm{H}_{2} \mathrm{O}$ ) which eliminated leaks out of the system (see Fig. 1). Its mixing characteristics were determined by observing the transit or delay time $\left(t_{1}\right.$, see Fig. 2) required for the instruments to start to react to the change in gas concentration beginning when the alcohol lamp was first ignited and was found to be 80 seconds. A major determinant of the speed, stability, response time, and sensitivity of this system was the dead space of the mixing chamber and wide bore respiratory tubing.
A multistage blower (Bodine Type NSE-13, Bodine Electric Company, Chicago, IL) was introduced between the expiration sampling site of the mixing chamber and the drying bottle (Fresh Dehydrite, Arthur H. Thomas Company, Philadelphia, PA) to maintain constant a flow of dry mixed expired gas $(150 \mathrm{ml}$ $\mathrm{min}^{-1}$ ) through the low range flowmeter B (no. R615B, Brooks Instrument Division, Hatfield, PA). The oxygen analyzer (Servomex A250, Taylor Instrument Company, Rochester, NY) was operated at a sampling rate of $30 \mathrm{ml} \mathrm{min}-1$ and had a $90 \%$ step response of $160 \mathrm{~s}\left(\mathrm{t}_{2}\right.$, see Fig. 2). The carbon dioxide analyzer (Cavitron Model PM-20, Anaheim, CA) was operated at a sampling rate of $60 \mathrm{ml} \mathrm{min}^{-1}$, and required $340 \mathrm{~s}$ to reach $90 \%$ of full deflection to respond to a square wave change in gas composition. We used a $1200 \mu \mathrm{F}$ capacitor to condition the signal from the $\mathrm{CO}_{2}$ analyzer and to improve the signal to noise ratio of the $\mathrm{CO}_{2}$ analyzer which further accentuated the time delay of this measurement. The output signals from the oxygen and carbon dioxide analyzers were recorded on a direct writing recorder (Type 2400, Gould Instruments, Cleveland, OH) which was calibrated to manufacturer's specifications against standards traceable to the National Bureau of Standards.

Oxygen, carbon dioxide, and nitrogen concentrations of the inlet and outlet gas stream were also monitored continuously with a mass spectrometer using atomic masses 32, 44, and 28, respectively (Perkin Elmer MGA1100A, Pamona, CA) as shown in Figure 1. The mass spectrometer was operated at a sampling rate of $60 \mathrm{ml} \mathrm{min}^{-1}$ and required $250 \mathrm{~ms}$ to reach $90 \%$ full deflection in response to a step change in gas composition. The analog signal from the mass spectrometer was digitalized with a laboratory microcomputer (MINC 11-23, Digital Equipment Corporation, Marlboro, MA) and recorded at 50 samples per second for each signal.

\section{RESULTS}

During the volumetric flow rate measurements we noted that the line inscribed by the pen attached to the spirometer was straight, as assessed by eye, over the entire evacuation period indicating that the air flow through the system generated by the blowers was stable. The coefficient of variation of repeated volume measurements timed over a range of $2-5$ liter $\mathrm{min}^{-1}$ on flowmeter $\mathrm{F}$ was $1.06 \%$ (range $0.49-1.94 \%$ ). The flow meter $\mathrm{F}$ attached to the outlet of the combustion chamber was accurate to $\pm 2 \%$ of the reading on the meter.

Although the flame was used to simulate the patient in clinical studies, no attempt was made to control the exact amount of alcohol burned and we believe that the slight variation in the height of the flame accounted for variation of the weight of alcohol burned. Evaporation of alcohol from the flask accounted for 0 to $0.16 \%$ of the total weight of alcohol consumed during the experiment. The heat of combustion $\left(\Delta \mathrm{H}^{\circ}\right.$ equations 1 and 2) measured by the temperature difference between the outlet (mixing chamber) and inlet (room air) gas stream ranged from 0.5 to $0.7^{\circ} \mathrm{C}$ with a coefficient of variation $<1 \%$ throughout the experiment.

Figure 2 shows a representative recording of the decrement of $\mathrm{O}_{2}$ concentration and increment of $\mathrm{CO}_{2}$ concentration from room air during an alcohol burn experiment. Usually the inspired gas was about $300 \mathrm{ppm} \mathrm{CO}_{2}$ and the mixed expired value was $5000 \mathrm{ppm}$. We found it necessary to use a known input signal as recommended in the instruction manual of the paramagnetic oxygen analyzer to prevent zero drift because of the high sensitivity of the instrument. Figure 2 shows that the response of the whole system was not very fast and that the delay time before stabilization of $\mathrm{O}_{2}$ and $\mathrm{CO}_{2}$ concentration after starting and ending the burn was about $5 \mathrm{~min}$. This was a result of the integrating action of the dead space of the mixing chamber, drying bottle, wide bore respiratory tubing, and the electronic filtering in the circuit. Adequate stability $( \pm 1 \%)$ of the $\mathrm{O}_{2}$ and $\mathrm{CO}_{2}$ concentration deflections was obtained for exactly $30 \mathrm{~min}$ utes after ignition (weight 1) and before snuffing the flame (weight 2), (see Fig. 2). 
Table 1. $\dot{V} \mathrm{O}_{2}, \dot{V} \mathrm{CO}_{2}$, and $\mathrm{RQ}$ of alcohol combustion using the open-circuit system

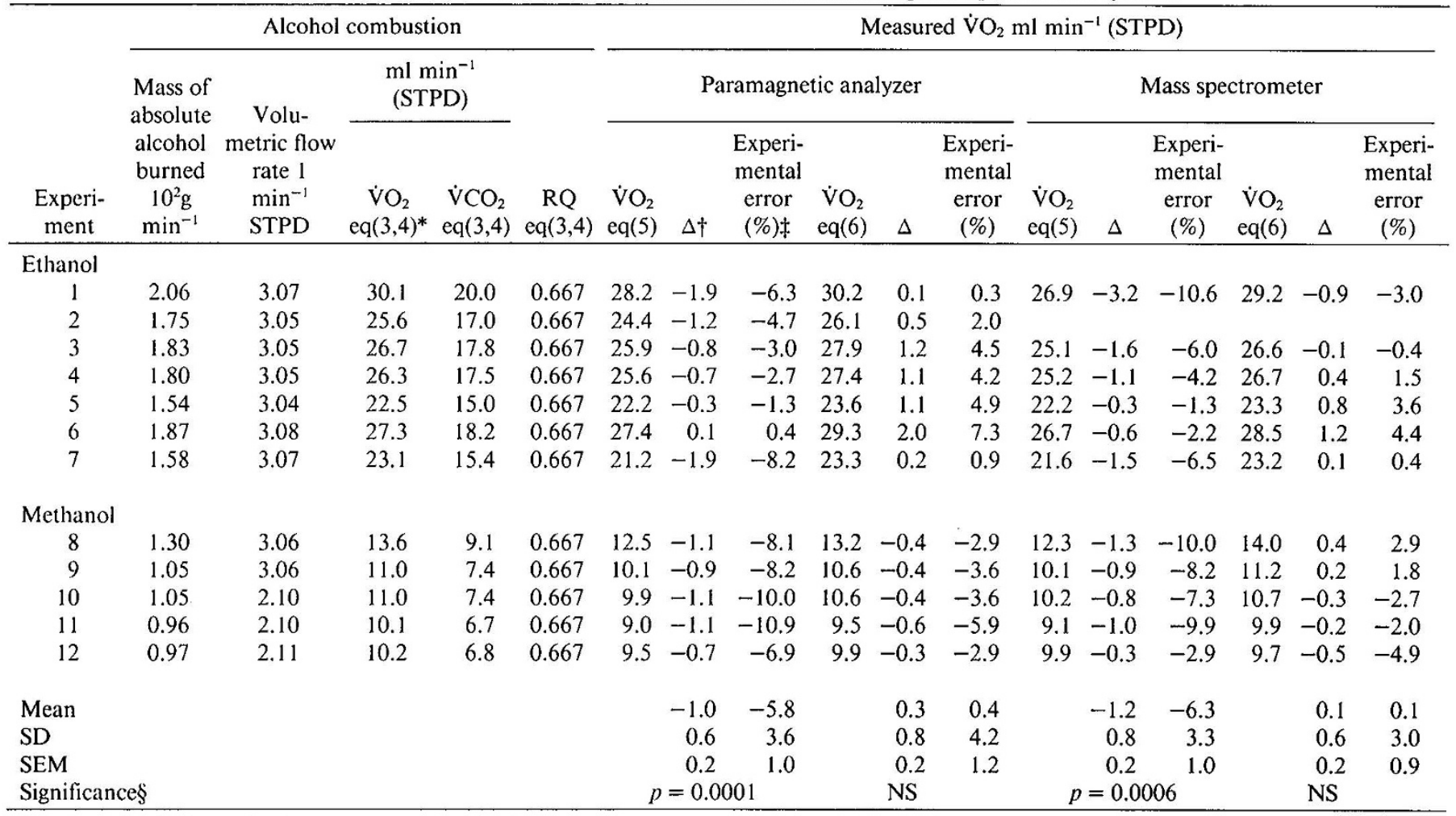

* See appendix for derivation and calculations using equations 3-8.

+ Difference $(\Delta)=$ measured value - true value .

$\$$ Experimental error $(\%)=[$ (measured value - true value $) /$ true value $] \times 100$.

$\S$ Test Ho:mean difference $=0$ by Student's $t$ test.

Table 1 shows the results of the comparative study between the paramagnetic oxygen analyzer, infrared $\mathrm{CO}_{2}$ analyzer, and mass spectrometer. Mean differences between the measured and true values were expressed along with their significance levels given by Student's $t$ test. When Haldane's correction was used in the calculation (equation 6), the experimental error in $\mathrm{VO}_{2}$ measured by the paragmatic oxygen analyzer averaged $0.4 \% \pm$ 4.2 SD of the $\mathrm{VO}_{2}$ value, whereas for $\dot{\mathrm{VO}}_{2}$ measured by mass spectrometer the mean experimental error was $0.1 \% \pm 3.0 \mathrm{SD}$ of the true $\mathrm{VO}_{2}$ value. (For paramagnetic $\mathrm{O}_{2}$ analyzer $p=0.194$, for mass spectrometer $p=0.657$ compared to true $\dot{\mathrm{V}} \mathrm{O}_{2}$.) A significant difference $(p<0.001)$ in measured $\dot{\mathrm{V}}_{2}$ compared to true $\dot{\mathrm{VO}}_{2}$ was found when equation 5 was used to calculate $\mathrm{V}_{2}$ for both instruments. For the infrared $\mathrm{CO}_{2}$ meter the mean experimental error for $\dot{\mathrm{V}}_{2}$ was $3.8 \% \pm 3.0 \mathrm{SD}$ versus a mean experimental error of $4.8 \% \pm 4.4$ for $\mathrm{VCO}_{2}$ when calculated from the mass spectrometer data. Mean differences from the true values for $\dot{\mathrm{V}} \mathrm{CO}_{2}$ were significant $\left(p<0.05\right.$ versus true $\left.\dot{\mathrm{V} C O}{ }_{2}\right)$ for both methods of gas analysis. From Table 1 it was apparent that for each analytical system, the mean values of the serial $\dot{\mathrm{VO}}_{2}$ and $\dot{\mathrm{VCO}}_{2}$ measurements were within $5 \%$ of the true values derived from the mass of absolute alcohol combustion. A positive bias was observed for the $\dot{\mathrm{V}} \mathrm{CO}_{2}$ measurements for both the IR meter and mass spectrometer with the result that the RQ measurements were significantly higher than the true ratio of 0.667 $(p<0.05)$. The mass spectrometer gave more precise $\mathrm{VO}_{2}$ results whereas less variance of $\dot{\mathrm{V} C O}{ }_{2}$ measurements was observed with the IR $\mathrm{CO}_{2}$ meter.

Figure 3 shows that there was an extremely good direct correlation between the measured (using equations 6 and 7) and true oxygen consumption and carbon dioxide production over the range of the alcohol combustion experiments $(p<0.001$; $R=0.99$ ). Linear regression analysis revealed a significant differ- ence (slope significantly different from 1 at $p=0.0125$ level) for $\mathrm{VO}_{2}$ measured with the paramagnetic $\mathrm{O}_{2}$ analyzer and for $\mathrm{VCO}_{2}$ measured with the mass spectrometer, respectively.

\section{DISCUSSION}

The experimental design and principles involved in burning a known quantity of ethyl alcohol in a device connected with respiratory apparatus was described in detail by Benedict (2). $\mathrm{He}$ suggested that when performing alcohol checks for the control of metabolism apparatus, the amount of alcohol burned should be, as nearly as possible, proportional to the metabolism of the subject subsequently to be studied. In his laboratory when metabolism apparatus for infants was being calibrated, only small amounts (about $1 \mathrm{~g} / 30 \mathrm{~min}$ ) of alcohol were burned in the respiration chamber. He used a modified mechanico-chemical combustion chamber device first described by Carpenter and Fox (23).

With our simplified form of alcohol combustion apparatus, the $\dot{\mathrm{VO}}_{2}$ and $\dot{\mathrm{VCO}}_{2}$ calculated from known amounts of alcohol combustion differed by $<5 \%$ from the true values. We used the difference between the thermochemical properties of methanol and ethanol (see equations 1 and 2) to simulate the variation in metabolism of the infants without having to change the height of the flame by altering the wick of the alcohol lamp thereby limiting alcohol loss by evaporation.

The electronic balance provided suitable accuracy and precision for measurement of the mass of alcohol consumed by combustion while monitoring mixed expired gas concentrations. The accuracy of determining the relative density of the alcohol to derive the anhydrous alcohol concentration however was limited by the accuracy with which the volume of the pycnometer could be determined. Errors $( \pm 2 \%)$ in the calculation of the true 


\begin{tabular}{|c|c|c|c|c|c|c|c|c|c|c|c|}
\hline \multicolumn{6}{|c|}{ Measured $\dot{\mathrm{V}} \mathrm{CO}_{2} \mathrm{ml} \mathrm{min}^{-1}(\mathrm{STPD})$} & \multicolumn{6}{|c|}{ RQ } \\
\hline \multicolumn{3}{|c|}{ IR meter } & \multicolumn{3}{|c|}{ Mass spectrometer } & \multicolumn{3}{|c|}{$\begin{array}{c}\text { Paramagnetic analyzer/IR } \\
\text { meter }\end{array}$} & \multicolumn{3}{|c|}{ Mass spectrometer } \\
\hline $\begin{array}{l}\dot{\mathrm{V} C O} \\
\mathrm{eq}(7)\end{array}$ & $\Delta$ & $\begin{array}{c}\text { Experi- } \\
\text { mental } \\
\text { error } \\
(\%)\end{array}$ & $\begin{array}{l}\dot{\mathrm{V} C O} \\
\mathrm{eq}(7)\end{array}$ & $\Delta$ & $\begin{array}{l}\text { Experi- } \\
\text { mental } \\
\text { error } \\
(\%)\end{array}$ & $\begin{array}{c}\mathrm{RQ} \\
\mathrm{eq}(8)\end{array}$ & $\Delta$ & $\begin{array}{c}\text { Experi- } \\
\text { mental } \\
\text { error } \\
(\%)\end{array}$ & $\begin{array}{c}\text { RQ } \\
\text { eq }(8)\end{array}$ & $\Delta$ & $\begin{array}{c}\text { Experi- } \\
\text { mental } \\
\text { error } \\
(\%)\end{array}$ \\
\hline 20.6 & 0.6 & 3.0 & 20.5 & 0.5 & 2.5 & 0.681 & 0.014 & 2.1 & 0.702 & 0.035 & 5.2 \\
\hline 17.1 & 0.1 & 0.6 & & & & 0.654 & -0.013 & -1.9 & & & \\
\hline 18.0 & 0.2 & 1.1 & 19.1 & 1.3 & 7.3 & 0.644 & -0.023 & -3.4 & 0.716 & 0.049 & 7.3 \\
\hline 18.3 & 0.8 & 4.6 & 18.8 & 1.3 & 7.4 & 0.668 & 0.001 & 0.1 & 0.704 & 0.037 & 5.5 \\
\hline 16.4 & 1.4 & 9.3 & 17.0 & 2.0 & 13.3 & 0.696 & 0.029 & 4.3 & 0.730 & 0.063 & 9.4 \\
\hline 19.7 & 1.5 & 8.2 & 20.1 & 1.9 & 10.4 & 0.672 & 0.005 & 0.7 & 0.705 & 0.038 & 5.7 \\
\hline 16.3 & 0.9 & 5.8 & 16.1 & 0.7 & 4.5 & 0.697 & 0.030 & 4.5 & 0.694 & 0.027 & 4.0 \\
\hline 9.5 & 0.4 & 4.4 & 9.5 & 0.4 & 4.4 & 0.720 & 0.053 & 7.9 & 0.679 & 0.012 & 1.8 \\
\hline 7.7 & 0.3 & 4.1 & 7.4 & 0 & 0 & 0.726 & 0.059 & 8.8 & 0.661 & -0.006 & -0.9 \\
\hline 7.3 & -0.1 & -1.4 & 7.5 & 0.1 & 1.4 & 0.689 & 0.022 & 3.3 & 0.703 & 0.036 & 5.4 \\
\hline 6.9 & 0.2 & 3.0 & 6.8 & 0.1 & 1.5 & 0.726 & 0.059 & 8.8 & 0.687 & 0.020 & 3.0 \\
\hline \multirow[t]{5}{*}{7.0} & 0.2 & 2.9 & 6.8 & 0 & 0 & 0.707 & 0.040 & 6.0 & 0.701 & 0.034 & 5.1 \\
\hline & 0.5 & 3.8 & & 0.8 & 4.8 & & 0.023 & 3.4 & & 0.031 & 4.7 \\
\hline & 0.5 & 3.0 & & 0.8 & 4.4 & & 0.027 & 4.1 & & 0.018 & 2.7 \\
\hline & 0.1 & 0.9 & & 0.2 & 1.3 & & 0.008 & 1.2 & & 0.006 & 0.8 \\
\hline & $p=0.003$ & & & $p=0.007$ & & & $p=0.014$ & & & $p=0.0002$ & \\
\hline
\end{tabular}
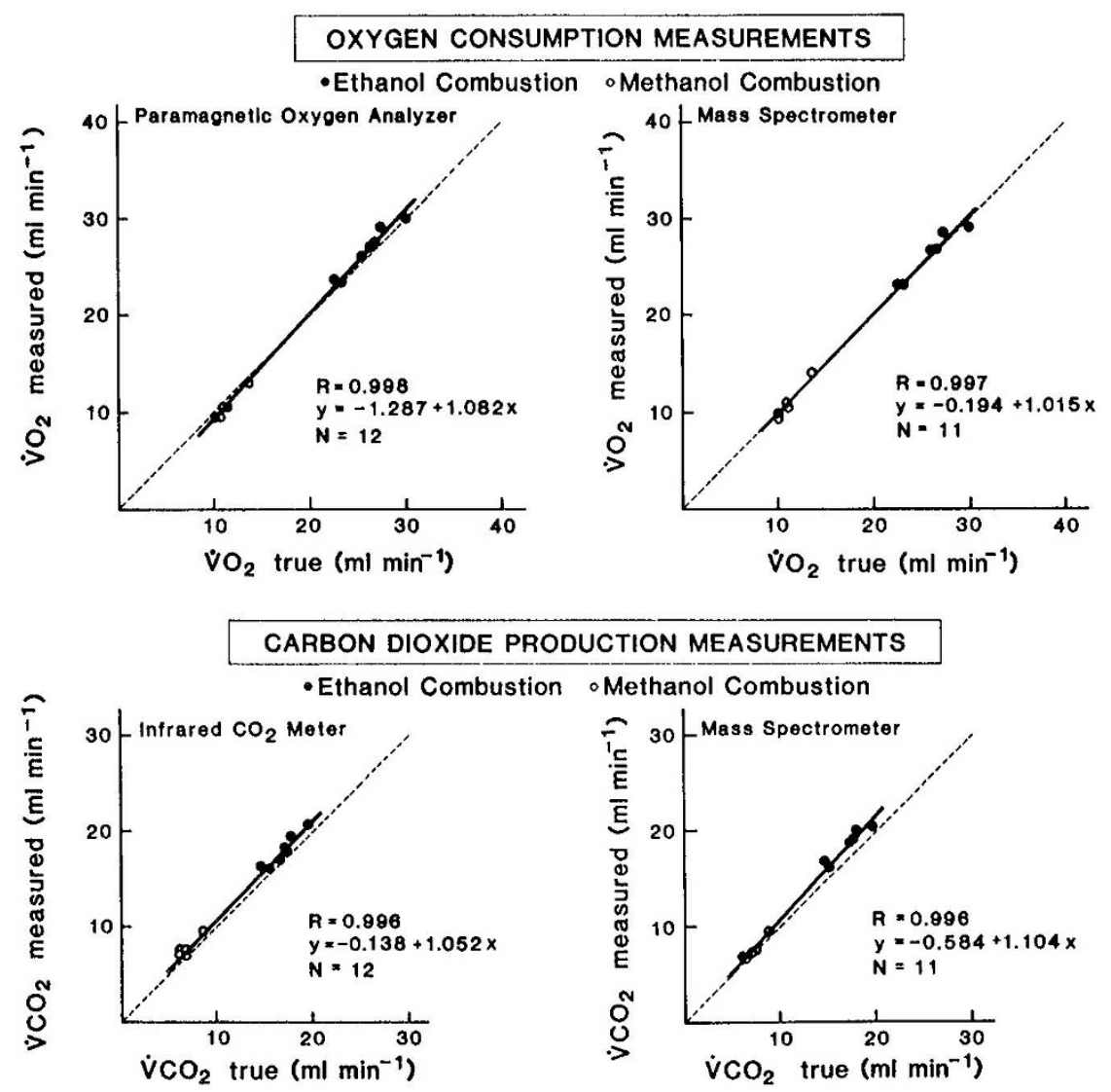

Fig. 3. Results of the open-circuit system validation experiments. Rates of $\dot{\mathrm{VO}}_{2}$ and $\dot{\mathrm{V}} \mathrm{CO}_{2}$ for ethanol and methanol combustion. Measurements were made with the open-circuit system in the laboratory. Note that $\dot{\mathrm{V}} \mathrm{O}_{2}$ and $\dot{\mathrm{V} C O}{ }_{2}$ values cover the range found in neonates. Solid line represents the least squares regression line of the equation $\mathrm{Y}=\mathrm{a}+\mathrm{bX}$. Broken line indicates line of identity. For $\dot{\mathrm{V}}_{2}$ measured with paramagnetic $\mathrm{O}_{2}$ analyzer, intercept significantly different from 0 and slope significantly different from 1 at $p=0.0125$ level. For $\dot{\mathrm{VCO}}_{2}$ measured with mass spectrometer slope significantly different from 1 at $p=0.0125$ level. 
$\dot{\mathrm{VO}} 2, \dot{\mathrm{V}} \mathrm{CO}_{2}$, and RQ may have been incurred at least in part by impurities, irregular or incomplete combustion, evaporation of the alcohol during burning, as well as by small errors introduced by the relative density measurements.

In determining oxygen consumption using data from the paramagnetic oxygen analyzer, we assumed that the composition of the input air stream remained constant $\left(\mathrm{FO}_{2_{\text {in }}}=20.93 \%\right)$. In the case of the $\mathrm{VO}_{2}$ measurement during the mass spectrometer data, however, the input and output stream oxygen concentration were measured and used in the calculations. Because the composition of inspired air remained relatively constant it seems likely that these small differences may account for the small differences in the calculation of the $\mathrm{VO}_{2}$ from mass spectrometer data. The results of $\dot{\mathrm{VO}} \mathrm{O}_{2}$ confirm the importance of using Haldane's transformation to correct for the difference between the volumetric flow rate at the inlet and outlet of the system during the alcohol combustion. From the values for $\dot{\mathrm{VO}}_{2}$ in Table 1 , it was apparent that the experimental error in $\dot{\mathrm{VO}}_{2}$ values for ethanol and methanol were in the opposite direction and may have resulted from impurities in the alcohol, irregular or incomplete combustion, evaporation during the burn, or the influence of water vapor (24). The accuracy and precision of the $\mathrm{VCO}_{2}$ measurements may have been influenced adversely by water vapor in the $\mathrm{CO}_{2}$ meter, incomplete combustion with possible carbon monoxide interfering with the IR meter, or a systematic error involving the carbon dioxide calibration gas. We did not check for isotope abundance or argon concentration of the outflow stream gas and theoretically may have influenced the mass spectrometer results.

There were many other contributing sources of error both systemic and random in relation to the accuracy and precision of measurement of $\dot{\mathrm{VO}}_{2}$ and $\dot{\mathrm{VCO}}_{2}$ using an open-circuit technique $(25,26)$. In practice, it was the measurement of $\mathrm{FO}_{2_{\text {in }}}, \mathrm{FO}_{2_{\text {out }}}, \mathrm{FCO}_{2_{\text {in }}}$, and $\mathrm{FCO}_{2_{\text {out }}}$ that required the most care in the calculation of $\dot{\mathrm{VO}} \mathrm{O}_{2}$ and ${ }^{\mathrm{V}} \mathrm{CO}_{2}$ using the open-circuit system. Because the values were close to each other in magnitude and their differences were small, there may have been a magnification of small errors when the Servomex was used to measure both $\mathrm{FO}_{2_{\text {in }}}$ and $\mathrm{FO}_{2_{\text {out }}}$. The error that may occur during the measurement of the oxygen concentration difference between the inlet and outlet air could be prevented by the precise synchronization of two oxygen sensors in the Servomex analyzer. Similarly, the carbon dioxide difference could be continuously recorded on a meticulously synchronized double channel $\mathrm{CO}_{2}$ analyzer system. The accurate determination of the absolute $\mathrm{O}_{2}$ and $\mathrm{CO}_{2}$ concentration of the inlet and outlet air was thus crucial to the successful measurement of $\dot{\mathrm{V}} \mathrm{O}_{2}$ and $\dot{\mathrm{V}} \mathrm{CO}_{2}$, given the dependence of these values on the difference between inspired and expired gas concentration. The method chosen to measure the gas concentrations must have.a sufficiently small absolute error so that any magnification of this error in the computation of the difference between inspired and expired gas concentration does not compromise the total $\dot{\mathrm{VO}}_{2}$ and $\dot{\mathrm{V}} \mathrm{CO}_{2}$ calculation. The accuracies of the modern oxygen and carbon dioxide analyzers available are 0.005 and $0.001 \%$, respectively, have minimum base line drift and a very stable gain.

It may have been possible to reduce the error with repetition of the above experiments although the probability of an alert operator repeating the same mistakes was small. A complete description of the method used to reduce the total inaccuracy of the open-circuit system measurements may be found in the companion paper (27). Whatever analytical system is used to determine the rates of respiratory uptake of $\mathrm{O}_{2}$ and excretion of $\mathrm{CO}_{2}$ it must undergo frequent checks if accuracies of $\pm 5 \%$ or better for $\dot{\mathrm{VO}}_{2}$ and $\dot{\mathrm{V}} \mathrm{CO}_{2}$ measurements are to be achieved. In using the alcohol combustion method in the controlled environment of the laboratory it was possible to arrive at the best available estimate of the total inaccuracy or uncertainty of the $\dot{\mathrm{V}} \mathrm{O}_{2}$ and $\dot{\mathrm{V}} \mathrm{CO}_{2}$ measurements to cover the range found in the neonate (27).

\section{REFERENCES}

1. Atwater WO, Benedict FG $1905 \mathrm{~A}$ respiration calorimeter with applicances for the direct determination of oxygen. Carnegie Institution, Washington, D.C., 42:1-193

2. Benedict FG 1925 The control of gaseous metabolism apparatus. Boston Med Surg J 193:583-591

3. Levine SZ, Wilson JR 1926 The respiratory metabolism in infancy and in childhood: I. Basal metabolism of children. Am J Dis Child 31:323-334

4. Gordon HH, Levine SZ, Deamer WC, McNamara H 1940 Respiratory metabolism in infancy and in childhood. XXIII. Daily energy requirements of premature infants. Am J Dis Child 59:1185-1202

5. Kalberg P 1952 Determinations of standard energy metabolism (basal metabolism) in normal infants. Acta Paediatr Scand 41(suppl 89):14-151

6. Brück K 1961 Temperature regulation in the newborn infant. Biol Neonat 3:65-119

7. Sinclair JC 1978 Temperature Regulation and Energy Metabolism in the Newborn. Grune and Stratton, New York, pp 1-240

8. Lister G, Hoffman JIE, Rudolph AM 1974 Oxygen uptake in infants and children: a simple method for measurement. Pediatrics 53:656-662

9. Marks KH, Gunther RC, Rossi JA, Maiseis MJ 1980 Oxygen consumption and insensible water loss in premature infants under radiant heaters. Pediatrics $66: 228-232$

10. Marks KH, Lee CA, Bolan CD, Maisels MJ 1981 Oxygen consumption and temperature control of premature infants in a double-wall incubator. Pediatrics 68:93-98

11. Consolazio CF, Johnson RE, Pecora JL 1963 Respiratory metabolism. In: Physiological Measurements of Metabolic Functions in Man. McGraw-Hill Book Co, New York, pp 6-9

12. Bentley JP 1983 Static characteristics of measurement system elements. In: Principles of Measurement Systems. Longman, New York, p 21

13. Eisenhart C 1962 Realistic evaluation of the precision and accuracy of instrument calibration systems. J Res Natl Bur Std 67C:161-187

14. Depocas F. Hart JS 1957 Use of the Pauling oxygen analyzer for measurement of oxygen consumption of animals in open-circuit systems and in a shortlag, closed-circuit apparatus. J Appl Physiol 10:388-392

15. Carpenter TM, Coropatchinsky YS 1942 A modified Noyons thermic diaferometer for respiratory gas analysis. Indust Eng Chem 14:159-163

16. Damask MC, Weissman C, Askanazi J, Hyman AI, Rosenbaum SH, Kinney KM 1982 A systemic method for validation of gas exchange measurements. Anesthesiology 57:213-218

17. Pietrzyk DJ, Frank CW 1979 Analytical Chemistry, 2nd ed. Academic Press, New York, pp 389-409

18. Peters JP, Van Slyke DD 1932 General chemical technique. In: Quantitative Clinical Chemistry. Methods, Vol II. The Williams \& Wilkins Company, Baltimore, pp 43-45

19. Lawton RW, Prouty LR, Hardy JD 1954 A calorimeter for rapid determination of heat loss and heat production in laboratory animals. Rev Sci Instr 25:370377

20. Kell GS 1967 Precise representation of volume properties of water at one atmosphere. J Chem Eng Data 12:66-69

21. Weast RC, Astle MJ 1982-1983 CRC Handbook of Chemistry and Physics, 63rd ed. CRC Press, Boca Raton, LA, pp 229-276

22. Newburgh LH, Johnston MW, Wiley FH, Sheldon JM, Murrill WA 1937 A respiration chamber for use with human subjects. J Nutr 13:193-201

23. Carpenter TM, Fox EL 1923 Alcohol check experiments with portable respiration apparatus. Boston Med Surg J 189:551-561

24. Beaver WL 1973 Water vapor corrections in oxygen consumption calculations. J Appl Physiol 35:928-931

25. Kappagoda CT, Linden RJ 1972 A critical assessment of an open circuit technique for measuring oxygen consumption. Cardiovasc Res 6:589-598

26. Young BA, Fenton TW, McLean JA 1984 Calibration methods in respiratory calorimetry. J Appl Physiol 56:1120-1125

27. Marks KH, Nardis EE, Derr JA 1987 Day-to-day energy expenditure variability in low birthweight neonates. Pediatr Res 21:66-71

\section{APPENDIX}

\section{Calculations. Alcohol combustion equations.}

The final products of complete combustion of absolute alcohol are carbon dioxide, water and heat. The combustion equation for ethanol is:

$$
\mathrm{CH}_{3} \mathrm{CH}_{2} \mathrm{OH}+3 \mathrm{O}_{2} \text { (burning) } \underset{3 \mathrm{H}_{2} \mathrm{O} \Delta \mathrm{H}^{\circ}=-326.68 \mathrm{kcal}}{2 \mathrm{CO}_{2}}
$$

and for methanol is:

$2 \mathrm{CH}_{3} \mathrm{OH}+3 \mathrm{O}_{2}$ (burning) $2 \mathrm{CO}_{2}$

$$
+4 \mathrm{H}_{2} \mathrm{O} \Delta \mathrm{H}^{\circ}=-347.28 \mathrm{kcal}
$$

The mole quantity or mass in grams of each factor in equations 1 and 2 is numerically equal to its molecular weight calculated from the standard table of atomic weights. For example, the molecular weight of ethanol, $\mathrm{CH}_{3} \mathrm{CH}_{2} \mathrm{OH}$, is $(2 \times 12.011)+$ 
$(15.999)+(6 \times 1.0008)=46.069$ and for methanol, $\mathrm{CH}_{3} \mathrm{OH}$, is $(12.011)+(15.999)+(4 \times 1.008)=32.042$. Assuming a standard abundance of isotope the molecular weight may be regarded as a pure number.

Equation 1 tells us also that for each mole of ethanol $3 \mathrm{~mol}$ of oxygen are required for a stoichiometric mixture. Since the volume occupied by a mol or a $\mathrm{g}$ molecular weight of any gas measured at standard conditions is 22.414 liter (21), then by expressing equations 1 and 2 in volume it may be predicted that during combustion:

$1 \mathrm{~g}$ ethanol consumes

$$
3 \times 22.414 / 46.069=1.460 \text { liters } \mathrm{O}_{2}(\mathrm{STP})
$$

and produces

$$
2 \times 22.414 / 46.069=0.973 \text { liters } \mathrm{CO}_{2}(\mathrm{STP})
$$

and

$$
3 \times 22.414 / 46.069=1.460 \text { liter } \mathrm{H}_{2} \mathrm{O}(\mathrm{STP}) .
$$

$1 \mathrm{~g}$ methanol consumes

$$
3 \times 22.414 / 64.084=1.049 \text { liter } \mathrm{O}_{2}(\mathrm{STP})
$$

and produces

$$
2 \times 22.414 / 64.084=0.700 \text { liter } \mathrm{CO}_{2}(\mathrm{STP})
$$

and

$$
4 \times 22.414 / 64.084=1.399 \text { liter } \mathrm{H}_{2} \mathrm{O}(\mathrm{STP}) .
$$

Using equations 3 and 4 the true values of $\dot{\mathrm{VO}}_{2}, \dot{\mathrm{V}} \mathrm{CO}_{2}$, and $\mathrm{RQ}$ of absolute ethanol and methanol for each combustion experiment was calculated. The following example uses data from combustion experiment 4 :

$0.541 \mathrm{~g}$ of ethanol burned in $30 \mathrm{~min}$.

Anhydrous alcohol concentration $=99.9 \%$ measured with pycnometer.

Mass of absolute ethanol burned

$$
\begin{aligned}
& =0.541 \times 0.999 \\
& =0.540 \mathrm{~g} / 30 \mathrm{~min} .
\end{aligned}
$$

From equation 3:

$$
\begin{gathered}
\dot{\mathrm{VO}}_{2}=0.540 \mathrm{~g} \times 1.460=0.788 \text { liter } \mathrm{O}_{2}(\mathrm{STPD}) / 30 \mathrm{~min} \\
\dot{\mathrm{V} C O}_{2}=0.540 \mathrm{~g} \times 0.973=0.525 \text { liter } \mathrm{CO}_{2}(\mathrm{STPD}) / 30 \mathrm{~min} \\
\mathrm{RQ}=\dot{\mathrm{V} C O}_{2} / \mathrm{V}_{2}=0.667
\end{gathered}
$$
tus.

Calculation of $\dot{\mathrm{V}} \mathrm{O}_{2}, \dot{\mathrm{V} C \mathrm{C}_{2}}$, and $\mathrm{RQ}$ from open-circuit appara-

The mean rate of oxygen consumption was expressed in terms of the fractional compositions $\left(\mathrm{FO}_{2_{\text {in }}}, \mathrm{FO}_{2_{\text {out }}}\right)$ and the flows $\left(\dot{V}^{2} i_{i n}\right.$,
$\left.\dot{V}{ } r_{\text {out }}\right)$ of the input and output gas streams, respectively, as follows:

$\mathrm{O}_{2}$ consumed $=\left(\dot{\mathrm{V}}_{\text {air }}{ }_{\text {in }} \times \mathrm{FO}_{2_{\text {in }}}\right)$

$$
-\left(\text { Vair }_{\text {out }} \times \mathrm{FO}_{2_{\text {out }}}\right) \text { liter } \mathrm{O}_{2}(\mathrm{STPD}) / \mathrm{min} \text {. }
$$

This calculation is based on the assumption that the RQ is 1 when Vair $_{\text {in }}=$ Vair $_{\text {out. }}$. During the alcohol burn, however, less $\mathrm{CO}_{2}$ is produced in relation to $\mathrm{O}_{2}$ consumed ( $\mathrm{RQ}$ for ethanol and methanol $=0.667)$. In this case the volume of air ${ }_{\text {out }}$ is $<$ Vair $_{\text {in }}$ and the nitrogen concentration represents a larger percentage of the output air compared to the input air. Assuming that inert gases, primarily nitrogen, are not consumed and are not accumulated in the combustion chamber (or in the lung), then $\dot{V}{ }_{i r}$ in may be related to Vair ${ }_{\text {out }}$ using the Haldane transformation:

$$
\dot{V}_{\text {air }}=\frac{\dot{\text { Vair }}_{\text {out }} \times \mathrm{FN}_{2_{\text {ous }}}}{\mathrm{FN}_{2_{\text {in }}}}
$$

Where $\mathrm{FN}_{2_{\text {in }}}=0.7904$ and $\mathrm{FN}_{2_{\text {out }}}=$ fractional composition of nitrogen in the output air computed form gas analysis as $\left[1-\left(\mathrm{FO}_{2_{\text {out }}}+\mathrm{FCO}_{2_{\text {out }}}\right)\right]$, recognizing that the sum of the respired gas fraction (on a dry basis) must be unity. Equation 5 can then be written as:

$$
\mathrm{O}_{2} \text { consumed }=\frac{\dot{\text { Vair }}_{\text {out }} \times \mathrm{FN}_{2_{\text {out }}} \times \mathrm{FO}_{2_{\text {in }}}}{\mathrm{FN}_{2_{\text {in }}}}-\dot{\text { Vair }}{ }_{\text {out }} \times \mathrm{FO}_{2_{\text {out }}}
$$

liter $\mathrm{O}_{2}(\mathrm{STPD}) / \mathrm{min}$.

The final form of the equation is:

$$
\dot{\mathrm{VO}}_{2} \text { measured }=\dot{\mathrm{V}}_{\text {air }}\left[\left(\frac{\mathrm{FN}_{2_{\text {out }}}}{0.7904} \times 0.2093\right)-\mathrm{FO}_{2_{\text {out }}}\right]
$$

liter $\mathrm{O}_{2}(\mathrm{STPD} / \mathrm{min}$.

The production rate of $\mathrm{CO}_{2}$ was calculated as follows:

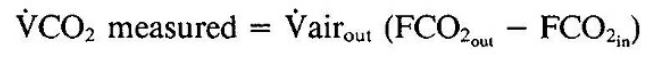

liter $\mathrm{CO}_{2}(\mathrm{STPD}) / \mathrm{min}$,

where $\dot{\mathrm{V}}$ air ${ }_{\text {ou }}$ was the velocity of the output gas stream, $\mathrm{FCO}_{2_{\mathrm{ou}}}$ and $\mathrm{FCO}_{2}$ the fractional composition of the output and input gas streams, respectively, as determined by gas analysis. Note that Haldane's correction was not necessary for $\mathrm{VCO}_{2}$ calculations (11).

The RQ was calculated as follows:

$$
\mathrm{RQ}=\frac{\dot{\mathrm{V} C \mathrm{C}_{2}}}{\dot{\mathrm{VO}_{2}}}
$$

These calculations assume that the exit air was dried before analysis and that air flow was calculated as dry air. 